\title{
Reflexões sobre política de formação e valorização do professor na contemporaneidade brasileira
}

\author{
Yáscara Michele Neves Koga Guindani ${ }^{1}$ \\ Evandro Ricardo Guindani2
}

\begin{abstract}
RESUMO
Este artigo resulta de uma pesquisa em nível de doutorado que teve por objetivo investigar a problemática da meritocracia na profissão docente. O tema da política de formação e valorização docente no Brasil contemporâneo deve ser tratado como um objeto complexo que exige uma observação e análise panorâmica ancorado em teorias fundantes, do contrário, a análise do tema desloca-se para um ponto cego, transformando um debate específico em matrizes gerais de explicação, que no limite cumpre o papel formal, mas não delineia apontamentos significantes. A pesquisa fez uso de levantamento bibliográfico que buscou refletir sobre os determinismos econômicos para o campo da educação utilizando para isso o conceito de tirania de Bourdieu (2001). Adentrando para o campo específico da determinação econômica para o campo da formação docente foi utilizado o conceito de refração do mesmo autor. E num último momento far-se-á uma análise do tema valorização docente no Brasil contemporâneo na perspectiva teórica do mérito.
\end{abstract}

Palavras-chave: Política de valorização docente. Meritocracia. Formação de professores

\section{Reflections on teacher education and valorization policy in brazilian contemporaneity}

\begin{abstract}
This article is the result of a doctoral level research that aimed to investigate the problem of meritocracy in the teaching profession. The theme of teacher education and valorization policy in the contemporary Brazil must be treated as a complex object that requires a panoramic observation and analysis anchored in founding theories. Otherwise, the analysis of the theme shifts to a blind spot, transforming a specific debate in general matrices of explanation, which in the limit fulfills the formal role, but does not delineate significant notes. The research used a bibliographic survey that sought to reflect on the economic determinisms for the field of education

\footnotetext{
1 Doutora em Educação pela PUC/SP. Professora da Universidade Federal do Pampa Campus São Borja-RS. Brasil. Orcid Id: https://orcid.org/0000-0002-1546-978X. E-mail: yascaraguindani@unipampa.edu.br

2 Doutor em Educação pela UFSC/SC. Professor da Universidade Federal do Pampa Campus São Borja-RS. Brasil. Orcid Id: https://orcid.org/0000-0002-8376-2531. E-mail: evandroguindani@unipampa.edu.br
} 
using Bourdieu's concept of tyranny (2001). Entering in the specific field of economic determination for the field of teacher education, it was used the concept of refraction by the same author. At a last moment, an analysis of the teaching valorization theme in the contemporary Brazil will be made in the theoretical perspective of the merit.

Keywords: Teacher appreciation policy. Meritocracy. Teacher education.

\section{Reflexiones sobre la formación docente y la políitica de valorización en la contemporaneidad brasileña}

\section{RESUMEN}

Este artículo es el resultado de una investigación a nivel de doctorado cuyo objetivo es abordar el problema de la meritocracia en la profesión docente. El objeto de la educación docente y la política de valorización en el Brasil contemporáneo debe tratarse como un objeto complejo que requiere una observación y análisis panorámicos anclados en las teorías fundacionales; de lo contrario, el análisis del tema se direciona hacia un punto ciego, transformando un debate específico. En general, las matrices de explicación, que en última instancia cumplen el rol formal, no delinean notas significativas. La investigación utilizó una pesquisa bibliográfica que buscaba reflexionar acerca de los determinismos económicos en el campo de la educación utilizando el concepto de tiranía de Bourdieu (2001). Al ingresar al campo específico de la determinación económica para el campo de la formación docente, se utilizó el concepto de refracción del mismo autor. Y en un último momento se realizó un análisis del tema de la valorización docente en Brasil desde la perspectiva teórica del mérito.

Palabras llave: Política de apreciación docente. Meritocracia. Formación de profesores

\section{Introdução}

Compreender esta temática - Política de formação e valorização do professor - é tarefa complexa, pois apresenta-se como um objeto de análise multifacetado. Desta forma, deste universo complexo foram pinçadas três facetas que avaliamos serem balizares no debate do tema. Dividimos o texto em três partes: a primeira parte aborda a face de cooptação da economia ao campo $^{3}$ da educação, esta face justifica-se considerando que é impossível qualquer debate sobre Política de formação e valorização do professor que ignore o peso das determinações econômicas sobre o campo

3 Campo compreendido pelo conceito formulado por Bourdieu (1983) como espaços hegemônicos que lutam pelo monopólio, autoridade, com poder de ditar regras e repartir capital específico. 
da educação. Para essa abordagem usaremos como fundamentação teórica o conceito de tirania de Bourdieu (2001), entre outros; a segunda parte apresenta-se como um desdobramento da primeira, pois analisaremos a face da política de formação, afim, de explicitar ao leitor como o tema desdobra-se na realidade política de formação do professor. A terceira parte deste trabalho - utilizando os dois desdobramentos anteriores como escopo - consiste na análise do tema valorização docente no Brasil contemporâneo na perspectiva teórica do mérito.

A referida pesquisa é uma pesquisa teórica que faz uso do método qualitativo. O procedimento técnico adotado é a pesquisa bibliográfica. Os principais conceitos e temas discutidos com o aporte bibliográfico serão: conceito de tirania (Bourdieu, 2001); Política de formação de professores (Shiroma, Moraes e Evangelista, 2007); Valorização docente (Pereira; Conceição \& Andrade, 2006).

O tema da política de formação e valorização docente no Brasil contemporâneo deve ser tratado como um objeto complexo que demanda observação e análise panorâmica ancorado em teorias fundantes, do contrário, a análise do tema desloca-se para um ponto cego, transformando um debate específico em matrizes gerais de explicação, que no limite cumpre o papel formal, mas não delineia apontamentos significantes.

Em suma, este texto objetiva apresentar ao leitor um painel estruturado, além de chaves de leitura deste objeto multifacetado possibilitando ferramentas para contínuos debates sobre o tema: política de formação e valorização do professor na contemporaneidade brasileira

\section{Educação e economia numa relação tirânica}

"Há tirania, por exemplo, quando o poder político ou econômico intervém no campo científico ou literário." Bourdieu (2001)

A relação do campo econômico com o tema educação e consequentemente da política de formação e valorização docente no Brasil contemporâneo apresenta-se como base desta primeira análise. 
O debate sobre educação e, consequentemente, da política de valorização docente, origina-se fora da escola, num campo de debate em tese, alheio à educação, o campo econômico. Esta primeira parte do texto refere-se a um destaque da relação osmótica entre economia e educação uma relação que se retroalimenta.

Segundo Chauí (2001) o poderio financeiro determina, diariamente, as políticas de vários Estados. Logo, nesta primeira parte trataremos da face da cooptação da economia ao campo da educação, usaremos como fundamentação teórica o conceito de tirania de Bourdieu (2001), portanto, tirania compreendida enquanto intervenção de um campo sobre o outro, neste caso específico do campo econômico para o campo educacional.

O campo econômico, mais precisamente a proposta neoliberal, cooptou vários campos, entre eles o campo da educação. Segundo Mèszaros (2005), poucos negariam hoje que os processos educacionais e os processos sociais mais abrangentes de reprodução estão intimamente ligados.

Mészáros (2006, p. 263) explica que "nenhuma sociedade pode perdurar sem seu sistema próprio de educação" e, nesse contexto, vamos verificar como as políticas educacionais se constroem e se transformam a partir das determinações econômicas. Quando se verifica uma grande transformação no sistema econômico, diante de uma crise, por exemplo, novas demandas são transferidas para a esfera educacional. Para fins de delimitação temporal, esta análise foi elaborada a partir da segunda metade do século XX, quando o capitalismo mundial assumiu - mais especificamente na Europa ocidental e América - nova configuração, chamada de neoliberalismo, já vigente, porém em uma escalada mais agressiva.

Segundo afirma Frigotto (1995), no final da década de 1970, com a ministra da Inglaterra, Margaret Thacher, e o Presidente dos Estados Unidos, Ronald Reagan, surgiu o chamado "remédio neoliberal" à crise enfrentada pelo capitalismo. Para o autor, o ideário neoliberal apresentou-se como uma alternativa teórica, econômica, ideológica, ético-política e educativa ao 
capitalismo do final do século XX. O neoliberalismo assumiu o perfil de um modelo econômico que se utiliza de estratégias políticas e até mesmo jurídicas para buscar saídas à crise capitalista. Essa nova roupagem que o capitalismo liberal assumiu, mais enfaticamente no final dos anos 1980, caracterizada como um novo liberalismo (neoliberalismo), no entendimento de Silva e Gentili (1996, p. 10) sintetiza um ambicioso projeto de reforma ideológica de nossas sociedades. Esse ambicioso projeto se traduz na "construção e a difusão de um novo senso comum que fornece coerência, sentido e uma pretensa legitimidade às propostas de reforma impulsionadas pelo bloco dominante". Importa destacar que essa reforma capitalista é gestada e idealizada no chamado primeiro mundo.

Na Inglaterra de Margareth Thacher, de acordo com Shiroma, Moraes e Evangelista (2007), houve a difusão de uma ideologia do consenso, na qual se disseminava a ideia de não haver outro mundo possível e que todas as pessoas precisavam se adaptar a essa nova realidade econômica que seria hegemônica e permanente, confirmando o processo tirânico. Seria, assim, inútil opor-se a essa realidade, mas, sim, caberia a todos adaptaremse e tirar proveito prático desse processo econômico irreversível.

Conforme explicam Frigotto e Ciavatta (2003, p. 95), as últimas décadas do século XX e o início do século XXI vêm marcados por profundas mudanças no campo econômico, sociocultural, ético-político, ideológico e teórico. E, para os autores, essas mudanças se explicitam por uma tríplice crise: do sistema capital, ético-político e teórico. No plano mais profundo da materialidade das relações sociais, está a crise da forma capital. Após um processo de expansão, o capitalismo entra em crise em suas taxas históricas de lucro e exploração. "A natureza dessa crise impulsiona a um novo ciclo de acumulação mediante, sobretudo, a especulação do capital financeiro. Essa acumulação, todavia, não é possível para todos". Diante disso, instaurase, então, uma competição feroz entre grandes grupos econômicos, corporações transnacionais. Segundo os autores, há toda uma produção ideológica com a função de afirmar um pensamento único, trazendo a ideia de uma solução única para a crise. Essa ideologia se traduz em palavras tais 
como: globalização, Estado mínimo, reengenharia, reestruturação produtiva, sociedade pós-industrial, sociedade pós-classista, sociedade do conhecimento, qualidade total, empregabilidade, entre outras. E a função dessas expressões está em justificar a necessidade de reformas profundas no aparelho do Estado e nas relações capital-trabalho. O que ocorreu, consoante ressaltam Frigotto e Ciavatta (2003), foi uma retomada dos mecanismos de mercado com o discurso de que as políticas sociais conduzem à escravidão, e a liberdade de mercado conduz à prosperidade. Com base nessa lógica, representantes dos países do capitalismo central produziram um documento conhecido como Consenso de Washington, o qual, como observam os autores, balizou a doutrina do neoliberalismo ou neoconservadorismo que orientou as reformas sociais nos anos de 1990.

O neoliberalismo intervém e determina uma lógica social em que todos os atores sociais precisam se adaptar a essa realidade situando as políticas sociais prejudiciais, e a liberdade de mercado libertadora, como confirmam Frigotto e Ciavatta (2003). Segundo os autores, foi uma retomada dos mecanismos de mercado com o discurso de que as políticas sociais conduzem à escravidão, e a liberdade de mercado conduz à prosperidade. O neoliberalismo é um projeto ambicioso que se propõe a uma reforma ideológica da sociedade, confirmando o processo tirânico. Segundo Silva e Gentili (1996) esse ambicioso projeto se traduz na construção e na difusão de um novo senso comum que fornece coerência, sentido e uma pretensa legitimidade às propostas de reforma impulsionadas pelo bloco dominante. Localizando a educação, portanto, a política de formação e valorização docente, nesta lógica neoliberal os autores afirmam que é como Mcdonaldizar a educação pensá-la como uma instituição flexível que deve reagir aos estímulos, os sinais, emitidos por um mercado educacional altamente competitivo.

Pensando num cenário competitivo, o neoliberalismo adota 0 deslocamento para $\mathrm{o}$ indivíduo da responsabilidade por sua sorte, seu sucesso ou seu fracasso. Este princípio, foi herdado do mentor liberal Adam Smith (1937) que prega que esforço natural de cada indivíduo para melhorar 
sua própria condição além de encaminhá-lo a uma melhor condição pode conduzir a sociedade à riqueza. Excluindo toda ou qualquer condição adversa precedente ou atual do indivíduo como variante da sua condição, apontando exclusivamente para a vontade do indivíduo sua sorte, em que os interesses do mercado são atendidos em detrimento das necessidades do indivíduo.

Em relação aos docentes segue a mesma receita, a da flexibilização, e da responsabilização individual, onde sua função, por vezes, é descaracterizada.

Diante do fatalismo neoliberal defendido por políticos e ideólogos 4 , principalmente a partir dos anos 1980, os ditos países desenvolvidos se reorganizaram em blocos econômicos para a entrada numa nova fase do capitalismo. Nesse processo de reorganização, vários organismos multilaterais foram criados com o objetivo de articular interesses dos países ricos e propor ações aos demais países. Uma dessas grandes instituições é o Banco Mundial.

Conforme Torres (2000), o Banco Mundial é a instituição que oferece publicações com receitas para as adequações dos países à lógica neoliberal, e essas recomendações são endereçadas aos países pobres, porém escritas na ótica e com os paradigmas dos países desenvolvidos. $\mathrm{Na}$ concepção do autor, em especial nas recomendações para a educação, existe um abismo entre o discurso internacional adotado pelo Banco Mundial e as realidades locais e regionais dos países pobres.

É possível verificar que a principal característica do neoliberalismo é a ampliação do raio de ação da lógica de mercado. No entendimento de Bianchetti (1999, p. 88), enquanto nas concessões liberal-sociais se reconhece a desigualdade derivada do modo de produção capitalista e se aceita a intervenção do Estado para diminuir as polarizações,

\footnotetext{
$4 \quad$ Por fatalismo neoliberal entende-se uma ideologia de resignação que passa a ser construída por países hegemônicos, principalmente nas duas últimas décadas do século XX. Uma obra que ficou muito conhecida por defender essa inevitabilidade do caminho neoliberal é o texto de Francis Fukuyama intitulado "O fim da História e o Último Homem", no qual ele defende ser o modelo liberal um modelo ideal de sociedade e que não haveria nenhum outro modelo que o suplantasse.
} 
[...] o neoliberalismo rechaça qualquer ação estatal que vá além da de ser um "árbitro imparcial" das disputas. A ideia do Estado Mínimo é uma consequência da utilização da lógica do mercado em todas as relações sociais, não reduzidas somente ao aspecto econômico (BIANCHETTI, 1999, p. 88).

A centralidade dessa reforma neoliberal está focalizada, como já citado, na tentativa de superar as crises enfrentadas pelo capitalismo, e um dos objetivos é dar mais autonomia e liberdade às instituições privadas e financeiras. O Estado deve ser mínimo e se responsabilizar apenas por algumas áreas como segurança pública e justiça. Segundo Silva e Gentili (1996), dentro da concepção neoliberal, o Estado é visto como ineficiente no gerenciamento das políticas públicas. O papel dele se limitou a gerir compensações, entretanto, para Peroni (2003), não se trata de um Estado mínimo genericamente, ou seja, mínimo apenas para as políticas sociais. Numa economia neoliberal, o Estado deve ser capaz de garantir a manutenção da ordem social, que é uma preocupação constante à medida que os problemas sociais se agravam com as consequências das reformas.

No que tange aos reflexos do neoliberalismo para a educação, de acordo com Mello (1999), no desenvolvimento e na implementação das políticas educacionais neoliberais, a qualidade da educação - assumida como bandeira pelos diferentes setores governamentais e empresariais adquire importância estratégica, como condição para o aprimoramento do processo de acumulação de riquezas e aprofundamento do capitalismo. A educação passa a assumir um importante papel na sustentação dos discursos dos grupos hegemônicos. Conforme Shiroma, Moraes e Evangelista (2007), foram retomados aspectos da Teoria do Capital Humano e assim foi difundida a ideia de que a educação seria um dos principais determinantes da competitividade entre os países. Na concepção das autoras, a educação seria o único instrumento e a única forma de as pessoas sobreviverem no processo de concorrência do mercado. 
Num estudo feito por Koga (2009) que tratou de analisar os professores tidos como modelares pelo Ministério da Educação numa premiação anual, intitulado Prêmio Professores do Brasil, a pesquisadora detectou que os professores premiados pela instituição - que detém o capital institucional de maior volume do Brasil, ou seja, o que oficialmente regula as relações da educação no país - são os professores que se adaptam as condições precárias impostas a eles, construindo práticas docentes de maneira heroica. Ainda no estudo, Koga (2009) aponta que são consideradas "práticas docentes" modelares projetos como: construção de banheiros, pois os alunos defecam no entorno da escola, uso de lixo num projeto intitulado Lixo que vira livro, porque o acesso ao material pedagógico deve ser improvisado; outro projeto premiado chamado Verminoses, no qual a docente premiada relata que não há tratamento de esgoto, desta forma, seus alunos expelem lombrigas, ou seja, a miséria usada como ferramenta de trabalho, a miséria institucionalizada recebendo uma premiação, e o Estado Mínimo vigorando, transferindo a responsabilidade e por vezes culpabilizando os docentes, escola e alunos.

Em suma, compreender o tema política de formação e valorização docente no Brasil contemporâneo só é possível se conduzido, contextualizado e atrelado a lógica neoliberal, em basicamente três pontos:

O primeiro diz respeito ao processo tirânico que a economia impõe sobre a educação, onde a educação perde seu espaço, em que o neoliberalismo impõe regras, receitas e metas impulsionadas como disse Silva e Gentilli (1996) pelo bloco dominante. Portanto o tema acerca da formação e valorização docente no Brasil, no limite, é reformulado em detrimento do interesse do bloco dominante.

O segundo diz respeito ao papel do Estado. O Estado, que poderia ser uma garantia dos atores sociais, apresenta-se como um Estado mínimo, as vezes reduzida ao de "arbitro imparcial" de disputas, conforme Bianchetti (1999) afirma, a serviço da lógica do mercado, desta forma, o tema da política de formação e valorização do professor, apresenta-se isolado, já 
que o princípio do neoliberalismo obedece a lógica do mercado e não as necessidades da sociedade.

O terceiro diz respeito ao deslocamento para o indivíduo de toda a responsabilidade, sua sorte, seja pelo sucesso ou pelo fracasso, onde o esforço pessoal, ou a falta dele é o que determina o futuro do indivíduo, desta forma, o tema da formação e valorização do professor, no limite, é postulado como uma responsabilidade individual.

Diante deste cenário, propomos observar neste segundo momento a configuração das políticas públicas educacionais referente a formação docente.

\section{Segunda face: a política de formação docente}

Esta segunda parte apresenta-se como um desdobramento da primeira, pois analisaremos a face da política de formação de professores contextualizada na lógica neoliberal.

Farei um recorte temporal deste estudo localizado nas últimas décadas do século XX, com destaque para a última, quando se intensificaram a proliferação de eventos e documentos internacionais voltados à educação e formação de professores

Ao fazer uma análise das políticas educacionais brasileiras, Shiroma, Moraes e Evangelista (2007) consideram que na década de 1970 crescia um movimento crítico que reivindicava mudanças no sistema educacional. Diagnósticos, denúncias e propostas para a educação eram veiculadas por meio dos novos partidos de oposição criados legalmente em 1979. Foram criadas nessa década associações científicas e sindicais da área da educação tais como a Associação Nacional de Pós-graduação e Pesquisa em Educação (ANPED), a Associação Nacional de Docentes do Ensino Superior (ANDES), a Conferência Nacional dos Trabalhadores em Educação (CNTE). Entre as bandeiras de luta dessa década, situam-se a exigência por maior valorização e qualificação dos profissionais da educação, um plano 
de carreira nacional com piso salarial unificado, e reestruturação dos processos de formação de professores.

Destaca- se, neste item, algumas das principais ações promovidas pelo Estado no que diz respeito à formação de professores, mais especificamente a partir da década de 1990. Com relação específica às políticas de formação docente, no ano de 1993, a Secretaria de Educação Fundamental do MEC publicou a série "Atualidades Pedagógicas", abordando temas como autonomia, gestão, avaliação e formação de professores. Em 1995, o MEC promoveu, com apoio da UNESCO, um grande seminário internacional intitulado "Professores: formação e profissão". Shiroma, Moraes e Evangelista (2007) destacam, desse evento, a observação da então Secretária de Política Educacional do MEC, Eunice Durham. Ela afirmou existir um círculo vicioso no qual o decréscimo na remuneração docente, a deterioração na carreira do magistério e a má qualidade na formação inicial do professor, bem como a má qualidade do ensino, seriam componentes de um reforço mútuo. No entendimento de Durham, as licenciaturas no país estavam falidas, e as universidades não realizavam a necessária articulação da teoria com a prática. Ela defendeu que o professor deveria ter uma formação semelhante a outro profissional como o médico, o engenheiro e o administrador, desconsiderando, assim, as especificidades da função docente bem como as diferenças entre as instituições de ensino e as organizações empresariais.

Ainda quanto à formação de professores, Shiroma, Moraes e Evangelista (2007) apontam que, no Governo de Fernando Henrique Cardoso, especificamente, no ano de 1996, houve um encontro coordenado pelo Ministério do Trabalho e Emprego, resultando na elaboração de um documento intitulado "Questões críticas da educação brasileira". Esse documento recomendou a revalorização da prática de ensino, a estruturação de planos de carreira com mecanismos de progressão funcional vinculado tanto à qualificação quanto ao desempenho em sala de aula e incentivos salariais à permanência em regência de classe. 
Sobre a reforma educacional promovida no Governo FHC, Shiroma, Moraes e Evangelista (2007) afirmam que nela se atribui ao professor um protagonismo fundamental. Nele, identificam as responsabilidades pelas mazelas do sistema público de ensino e o mágico poder de extirpá-las. O professor precisaria se envolver com a reforma, como sugeriu o Relatório Delors. "O que a reforma patenteia é a produção por meio do professor das competências demandadas pelo mercado" (SHIROMA; MORAES; EVANGELISTA, 2007, p. 82). Segundo as autoras, as diretrizes curriculares pautadas na formação de valores, atitudes e comportamentos articulam-se colocando o professor no centro da realização do plano governamental. $\mathrm{Na}$ análise dos documentos internacionais que se refletem nas políticas nacionais de formação de professores, as autoras consideram que se verifica uma visão problemática sobre a questão da profissionalização docente, visto que supõe simultaneamente que ele não é profissional e que ele deve ser profissionalizado. Exige-se também, do professor, que ele saiba fazer, seu trabalho que supere o descompasso entre sua prática de ensino e de vida. Nesses documentos, há um esforço em convencer o professor de que ele precisa de uma profissionalização diferenciada da sua formação original, ou seja, busca retirar "a identidade construída historicamente pelo professor, esvaziando de seu sentido original e em seu lugar constrói outra mentalidade, competitiva e individualista. Um dos resultados disso no Brasil é a quebra da organização sindical" (SHIROMA; MORAES; EVANGELISTA, 2007, p. 83).

No Brasil, de acordo com as autoras, a Associação Nacional pela Formação de Profissionais da Educação (ANFOPE), em seu Documento Gerador, assinala que as reformas empreendidas nos anos de 1990 caracterizam-se por seu objetivo de adequar o sistema educacional ao processo de reestruturação produtiva e aos novos rumos do Estado. Nesse processo, coloca-se estrategicamente no centro das suas ações, a formação de profissionais da educação usando, como legitimação para várias reformas, o consenso social sobre a necessidade de se realizarem modificações na educação. 
As autoras salientam que dados de 1998 coletados pelo MEC revelam que mais de 100 mil professores não haviam completado o primeiro grau e outros 100 mil tinham apenas o primeiro grau. Na sinopse estatística de 1996 , o Brasil contava com um déficit de 1,2 milhões de professores na educação básica. Para fazer frente ao contingente de professores a serem formados, foram criados dois programas de informatização implementados pelo governo: o Programa Nacional de Tecnologia Educacional (PROINFO) ${ }^{5}$ e o Programa de Formação de Professores em exercício (PROFORMAÇÃO). O PROINFO tem por objetivo capacitar professores para uso das tecnologias; o PROFORMAÇÃO implementa curso de nível médio com habilitação para o magistério dirigido aos professores das 4 séries iniciais do ensino fundamental sem essa formação básica.

Conforme observa Campos (2002), esse contexto da reforma brasileira, brevemente traçado, converge com as tendências verificadas pela UNESCO, nas reformas em outros países. Segundo esse organismo, as políticas educacionais atuais se caracterizam por duas tendências: a) uma vontade afirmada de democratizar a educação; e b) a presença de uma concepção produtivista da qualidade e dos objetivos educacionais. Termos como avaliação, ajustamento, eficácia, performance e resultados revelam o quanto essas concepções vêm pressionando, há pelo menos 30 anos, as políticas educacionais. Ligada a essas duas tendências, há uma terceira, que consiste em imputar uma "responsabilidade pelos resultados", associada ora às políticas de descentralização, ora às exigências de eficácia e performance. Para a autora, de acordo com a UNESCO, os professores estão entre dois fogos, sendo vistos, de um lado, como aqueles que devem esclarecer as trevas, ensinando a tolerância, a compreensão internacional e o respeito aos direitos do homem, e de outro, como um custo, um fator de produção de uma empresa que absorve uma parte considerável do orçamento do Estado.

5 O PROINFO, no início denominado Programa Nacional de Informática na Educação, posteriormente teve seu nome alterado para Programa Nacional de Tecnologia Educacional, mas a sigla permaneceu inalterada. 
Sobre o conceito de professor competente cabe citar uma análise de Campos (2002) acerca do documento "Proposta de Diretrizes Curriculares para a Formação de Professores da Educação Básica" (BRASIL, 2000). Para a autora, no referido documento, os objetivos da formação inicial de professores encontram-se claramente definidos com relação à aquisição de competências.

\section{A valorização docente}

Nesta terceira fase, utilizando os dois desdobramentos anteriores como escopo, analisaremos o tema valorização do professor na perspectiva teórica da meritocracia.

Foram criadas no contexto neoliberal várias associações e bandeiras de lutas, entre as bandeiras de luta dessa década, situam-se a exigência por maior valorização e qualificação dos profissionais da educação, um plano de carreira nacional com piso salarial unificado, e reestruturação dos processos de formação de professores.

A busca pelo reconhecimento da atividade docente constitui aspecto do reconhecimento simbólico identificado como elemento importante na história do magistério, conforme pode ser observado pelo estudo de Vicentini (2002) acerca do Dia do Professor no Brasil. Para essa autora, em muitos casos, o reconhecimento simbólico do professor missionário parece superar a importância do retorno material recorrente nas demais profissões. Muitas vezes, quem pretende seguir a carreira docente é previamente avisado do salário aviltante e das más condições de trabalho de uma carreira condenada à humildade. Dentro dessas condições, a recompensa simbólica toma proporção essencial de um reconhecimento social. Percebese, portanto, a complexidade do estudo sobre a função docente, que contempla questões como: valorização docente, o reconhecimento simbólico, e a distinção dessa função. A distinção na esfera da docência, assim, apresenta-se como importante eixo. A distinção das premiações e gratificações apresenta-se, então, como um dado importante para a 
construção deste objeto de estudo no enfoque aqui enunciado, pois no levantamento realizado percebeu-se que a valorização docente vem sendo abordada com ênfase na profissionalização em torno de temas mais próximos da formação inicial e continuada assim como de carreira, conforme o estudo de Mello (2010) que encontrou 20 trabalhos realizados entre 1996 e 2006. A lógica neoliberal vem, portanto, fundamentar políticas educacionais que se traduzem na instauração da meritocracia como carro chefe da profissionalização e valorização docente.

Mais especificamente no que tange ao campo educacional, essa preocupação com a qualidade vai demandar um modelo de avaliação do trabalho docente centrado na produtividade do mesmo, daí a entrada da lógica do mérito em ações políticas de valorização e avaliação docente.

O Ministério da Educação também defendeu uma política - neste viés - para a valorização do trabalho docente conforme declaração do então Ministro da Educação:

Em entrevista ao jornal O Estado de S. Paulo, Haddad reconheceu que o Brasil ainda não dispõe de um modelo de valorização do magistério, afirmou que é preciso melhorar a qualidade do ensino médio e admitiu a carência de programas para atender crianças de até 3 anos. O ministro ainda defendeu a promoção por mérito aos docentes. "Sou favorável à promoção por mérito. Elaborar uma carreira que leve em consideração o mérito e negociar com a categoria como aferir isso de maneira a considerar o esforço do professor é louvável", afirmou Haddad. Para ele, o governo precisa cumprir a promessa feita em 2007 de criar uma prova nacional de admissão para professores. (HADDAD DEFENDE...2010)

Outros dois estudos sobre o tema trazem dados complementares. Vasconcelos (2006), ao estudar o bônus professor constatou que a política de bonificação afeta a atividade docente na medida em que valoriza excessivamente a mensuração de dados estatísticos, a divisão do trabalho e a impessoalidade na avaliação do trabalho desenvolvido pelas escolas e pelos professores, em detrimento da valorização das práticas de ensino e do processo de aprendizagem. Já o estudo de Alcântara (2010), ao analisar os mecanismos de controle por meio da bonificação, aponta que o discurso da 
meritocracia de valorização do magistério paulista adotado pelo poder público, assumidamente excluiu aqueles que tiveram um desempenho aquém do esperado, desconsiderando por completo fatores que são determinantes para o sucesso ou o fracasso do processo pedagógico.

Manifestações como as da professora entrevistada por Fernandes (2010), cujo excerto segue, referem-se ao bônus mérito implantado no Estado de São Paulo, complementa com dados detalhados o que já foi citado anteriormente:

O bônus amarrou o professor, destruiu a capacidade de mobilização, destruiu o professor como sujeito formador e está destruindo o professor como pessoa, como sujeito, porque cria uma alienação, uma dependência, e ele não se reconhece mais como sujeito, ele perde o ânimo. (FERNANDES, 2010, p.8)

Essas considerações põem em foco, portanto, aspectos problemáticos e negativos do uso da medida indicando evidências iniciais da necessidade de novas investigações que aprofundem os conhecimentos sobre esta relação tão instigante e estimulante entre docência e meritocracia, principalmente pelo fato de que esses princípios se traduzem em políticas de formação e valorização docente no Brasil.

Outro exemplo, no segundo semestre de 2009 o Governo do Estado de São Paulo divulgou um jornal direcionado à classe docente com o título: Valorização pelo Méritob. Em linhas gerais a Secretaria da Educação divulga suas novas diretrizes para tornar a carreira docente mais "atrativa". No texto inicial apresenta-se a possibilidade do docente multiplicar seu salário inicial, por até quatro vezes. Em destaque está a seguinte afirmação: esses ganhos salariais poderão ser conquistados pelos professores mediante seu próprio empenho e dedicação. O bônus mérito foi instituído em 2001, na rede estadual paulista, portanto não é tão recente. Inicialmente havia vinculação estreita com a busca de diminuição das faltas dos professores. Essa intenção foi gradativamente alterada. A cada governo as especificações do mérito se modificaram, conforme os dados analisados por Spinelli (2009). A partir de

6 Disponivel http://www.saopaulo.sp.gov.br/spnoticias/lenoticia.php?.id=205640\&c=6 acesso em outubro de 2009. 
2009 as alterações passaram a ser mais exigentes de modo que, para ser merecedora do prêmio, a escola toda precisa estar envolvida, pois além da frequência às aulas, foram inseridos outros requisitos, tais como as notas dos alunos nas provas de avaliações externas, taxas de evasão e repetência de alunos, envolvendo, portanto, substantivamente os professores, mas também outros agentes da escola que também recebem o bônus.

Conforme Spineli (2009), o bônus mérito é uma gratificação instituída fazendo parte da política estadual para a valorização do magistério. Por outro lado, quando o autor se debruça sobre as modificações da caracterização do bônus, observa várias modificações no texto original atrelando o bônus como regulador, resultante de uma combinação de pontuação que não é divulgada, o que segundo o autor pode ter levado ao descrédito do critério. Enfim, valorização, avaliação, bônus, combinação de pontuação, em meio à identidade docente, alardear da categoria profissional, afinal no que consiste a política de meritocracia na docência?

Este tipo de "valorização" salarial converge com que descrito por Shiroma (2007) em que a Conferência Ibero-Americana de Educação prescreve uma melhoria salarial do tipo individual, e não como ganho coletivo. Pelo que se pode observar não foi um avanço, já que o professor veterano perdeu seu benefício, sendo interessante somente para o professor em início de carreira, mas, mesmo assim, a incorporação foi para alcançar o piso, o que já era garantido por lei.

A economia está tão presente no campo da educação, que as contas não fecham com a proposta de valorização, acabam forçando o governo a buscar brechas para cumprir a demanda de maneira legal em relação à proposta da meritocracia. O mesmo aconteceu em São Paulo, quando os professores perceberam que a pontuação não condizia com a realidade, era irreal, impossível.

Assim percebe-se que a meritocracia vai se constituindo como disposição, integrando o habitus inerente à profissão docente. A política de valorização docente pela premiação e reconhecimento individual vai sendo incorporada dentro do próprio grupo. De acordo com Bourdieu (2005b) os 
elementos que constituem o habitus, quando forem regulares e permanentes, acabam se incorporando e transformando-se em esquemas de pensamento próprios das classes que engendram determinadas práticas. É um modus operandi repetitivo das mesmas práticas que farão com que estas constituam parte do habitus.

Para o autor, há uma supervalorização dos aspectos comerciais e reforço da ideologia do individualismo, de um darwinismo social e do consumismo.

Para compreendermos a relação entre magistério e meritocracia, necessitamos entender que o conceito de meritocracia é praticado na educação brasileira há algumas décadas. Segundo Rossi (1980) há na meritocracia uma promessa de mobilidade social oferecida às classes populares resultando na vitória através da "livre competição". Esta igualdade de competição seria ponto chave desta ideologia para a qual o "esforço" e o "trabalho duro" permitem o acesso às melhores posições. A meritocracia concentra no indivíduo a responsabilidade pelo seu sucesso ou seu fracasso esterilizando toda ou qualquer crítica ao entorno de sua ação. Em uma meritocracia o indivíduo é considerado como tendo "livre escolha", capaz de ir tão alto quanto sua motivação, desejo e habilidade o levem. Um indivíduo que não alcance o sucesso, só tem a si próprio para culpar, desde que não tenha tirado vantagem dos meios a ele disponível. (CARNOY, 1975, p.1, apud ROSSI, 1980, p.71)

No Brasil a meritocracia na educação apareceu de diversas formas. Uma delas é a premiação, conferindo distinção simbólica, conjugada ou não com a distinção material ou distinção em relação à posição ocupacional. Os Prêmios instituídos pelo Ministério da Educação assumiram essa função de criar o professor modelar, e o premia com o objetivo de suscitar e promover esses exemplos de sucesso. É o que a institucionalização da meritocracia pretende. Essa lógica meritocrática está sendo inserida na política de valorização docente e a grande questão que surge é: os docentes resistirão a isso ou farão uma adesão, legitimando tal política? Como se dará esse processo de assimilação da meritocracia entre os 
docentes? Segundo Bourdieu (1992) o professor luta por algo que está além das recompensas, quer dizer, "o lucro de ação presente, para sair da indiferença pretendendo se afirmar como agente ativo, preso ao jogo subjetivo da missão social" (p.49). O vestuário, a alimentação e os bens culturais conferem certa distinção delimitando um agente do outro.

A luta pela distinção pode ser pautada pela posse do título de professor que, em determinadas circunstâncias e para certos segmentos sociais confere certa diferenciação, sobretudo em relação aos trabalhadores manuais. Em um exemplo, conforme Pereira; Conceição \& Andrade (2006), sobre a região Nordeste do Brasil, algumas professoras chegavam a receber $\mathrm{R} \$ 15$ por mês. Mesmo ganhando pouco em relação ao sudeste e sul do País, essas professoras da pesquisa fazem parte, da "elite" do município mesmo sem disso ter consciência. De acordo com os autores, essas professoras têm rendimentos fixos e não trabalham na lavoura, numa região onde predomina o trabalho manual e sazonal. Essas professoras veem a profissão docente como recompensa ao seu esforço e por isso se autoconferem um grau de distinção:

\footnotetext{
Filhas de trabalhadores rurais e urbanos, analfabetos e semianalfabetos (exceto, mas, cujo pai havia completado o $2^{\circ} \mathrm{grau}$ ), conseguiram fugir, de algum modo, ao destino comum do trabalho manual, e isso constitui para elas enorme fonte de satisfação pessoal ("me sinto recompensada"; "a minha profissão é gratificante"). Por meio de investimentos materiais e, sobretudo, afetivos, tão mais duramente suportados ("muito lutei para chegar aonde cheguei") quanto maior as dúvidas e dificuldades enfrentadas, essas professoras conseguiram se situar num ponto do espaço social que, correlativo ao espaço físico onde atuam, permite o ganho de posição, isto é, essa forma propriamente não-capitalista de acumulação de capitais caracterizada pela posse de um capital distintivo (no caso, ser professora num município pobre). (PEREIRA; CONCEIÇÃO \& ANDRADE, 2006, p.10)
}

A profissão docente confere a essas mulheres uma distinção até mesmo em relação às demais mulheres quando afirmam ser cortejadas pela população masculina. Para os autores, as professoras afirmaram que os rapazes solteiros dos locais de suas escolas consideravam-nas "bonspartidos", mirando-as a partir de suas estratégias matrimoniais. A distinção 
conferida a elas pela população converte-se em motivação para superar as adversidades decorrentes da precariedade das políticas educacionais naquela região:

\begin{abstract}
"Me sinto valorizada pelos pais dos meus alunos"; "aquele abraço espontâneo e o sorriso largo que vejo em seu rostos todas as manhãs"; "somos tratadas com muito carinho, respeito e admiração por parte dos moradores das comunidades, e isso nos gratifica e estimula a enfrentar os problemas cotidianos". (PEREIRA; CONCEIÇÃO \& ANDRADE, 2006, p.10)
\end{abstract}

Para os autores, mesmo num universo aparentemente homogêneo, há hierarquia de funções, o que reduz os créditos simbólicos aos postos considerados mais baixos - segundo a percepção dos agentes, por exemplo, as professoras da educação infantil ou da creche. O que as mantém na profissão segundo Pereira; Conceição \& Andrade (2006) é a "adesão manifesta" ao carisma profissional, obtendo uma atitude antieconômica dos agentes, recusando o cálculo exclusivamente econômico. Coagidas pelas urgências, elas encontram no carisma da função a fonte de motivos para permanecer na profissão. No espaço analisado pelos autores o carisma define-se como propriedade simbólica central do magistério. No sentido empregado por Weber lapud Pereira; Conceição \& Andrade, 2006) "onde existe, uma 'vocação'", no sentido enfático da palavra, há uma "missão" ou "tarefa íntima" 7.

Segundo Pereira; Conceição \& Andrade (2006) o carisma é propriedade extra cotidiana para os agentes no topo dos campos simbólicos (autores, grandes acadêmicos, escritores de renome, entre outros) e é missão para os alocados nos postos mais baixos das escalas intelectuais (professores de séries iniciais, alfabetizadores de adultos). Também segundo Weber (apud Pereira; Conceição \& Andrade, 2006) é

\footnotetext{
$7 \quad$ Weber (2001, p. 64) aborda o conceito de vocação como algo peculiar dos protestantes: "Vocação é um termo que remete à ideia de uma tarefa confiada por Deus. Nem os povos católicos e nem os da antiguidade clássica possuíam qualquer expressão que tivesse tal conotação, do que hoje chamamos de vocação (no sentido de uma tarefa de vida, de um campo definido no qual trabalhar), enquanto que ela existiu para todos os povos protestantes". Na concepção weberiana, a ideia de vocação está ligada à profissão.
} 
uma atitude antieconômica, não porque o agente carismático recuse retornos materiais, mas porque recusa toda a atitude econômica racional, a perseguição exclusiva de fins estritamente econômicos:

O carisma é o centro de toda uma lógica da prática simbólica. Constitui uma espécie de operador prático que transforma os déficits (de posição, de localização, etc.) em rendimentos simbólicos pessoais. O agente carismático sente compensações íntimas mesmo nas tarefas socialmente mais desprezadas. O carisma supre o agente de imaginação auto justificadora: essa pode ser interpretada tanto como fonte de sentido quanto de eufemismo. É fonte de sentido, pois é da vocação que o agente do magistério extrai a sua libido profissional. Também opera como eufemização das mazelas crônicas de uma profissão dominada, situada nos níveis mais baixos das hierarquias simbólicas. Ao suportar o dia-a-dia de uma profissão que promete muito e cumpre pouco, o agente do magistério, ocupante de postos mais humildes nas hierarquias funcionais, encontra no carisma um "fundamento cotidiano duradouro. (PEREIRA; CONCEIÇÃO \&ANDRADE, 2006, p.14).

É nessa mesma direção que Bourdieu \& Champagne (1998), ao abordarem os "excluídos do interior" do sistema educacional apontam os que compõem o conjunto dos que descobrem que não têm as credenciais suficientes para ter acesso a posições sociais mais vantajosas. Segundo Pereira et al (2006), as professoras situadas nos postos mais baixos são os excluídos do interior do universo da produção simbólica. Fervorosas da democratização do ensino são as primeiras vítimas, pois perdem o valor distintivo de suas credenciais. Desta forma, a existência real de grande volume de certificados ou diplomas existentes distancia as professoras da distinção.

\section{Considerações finais}

Esta pesquisa buscou demonstrar como a educação não pode ser vista e compreendida de maneira isolada, apenas entre as quatro paredes da escola. A educação e o campo econômico são elementos indissociáveis. A referida pesquisa analisou mais especificamente a década de 2000 a 2010 , porém, em 2019 e 2020 é possível perceber no discurso de gestores públicos uma naturalização de conceitos e nomenclaturas próprios do campo econômico serem transferidos para o campo educacional. 
Este texto contribui para identificar os elementos que compõem a meritocracia na educação no que se refere à docência. Assim, foi possível, ao mesmo tempo, compreender os elementos que compõem a meritocracia e a docência advindas da política neoliberal e os seus efeitos na condição docente.

O estudo verificou que a meritocracia na docência é resultante de imposições econômicas ao campo educacional, portanto, esta é a primeira face conclusiva do estudo. Verifica-se, no estudo, o que Bourdieu chamou de tirania de um campo sobre outro campo. Com o estudo pode-se observar que, quando houve uma grande transformação no sistema econômico, diante da crise do capitalismo novas demandas foram transferidas para a esfera educacional. O neoliberalismo acirrado assume 0 perfil de um modelo econômico que se utiliza de estratégias políticas e até mesmo jurídicas para buscar saídas à crise capitalista. Trata-se de estratégia neoliberal que fornece elementos e princípios impulsionados pelo bloco dominante e disseminados mundialmente. Neste movimento tirânico do campo econômico para o campo educacional disseminou-se a ideia de não haver outro mundo possível e que todas as pessoas precisavam se adaptar a esta nova realidade econômica que seria hegemônica e permanente. Esta ideologia se traduz em palavras tais como: globalização, Estado mínimo, reengenharia, reestruturação produtiva, sociedade pósindustrial, sociedade pós-classista, sociedade do conhecimento, qualidade total, empregabilidade, dentre outras. E a meritocracia apresenta-se como catalisadora deste ideal.

Verifica-se no estudo, que algumas instituições interferiram, e interferem diretamente nos rumos da educação e uma delas é o Banco Mundial, instituição que oferece publicações com receitas para as adequações da educação dos países à lógica neoliberal, e estas recomendações são endereçadas aos países pobres, porém escritas na ótica e com os paradigmas dos países desenvolvidos. Nessas recomendações para a educação, existe um abismo entre o discurso internacional veiculado pelo Banco e as realidades locais e regionais dos 
países pobres. Com base nessas reflexões novas pesquisas poderão ser feitas em torno da relação entre educação e economia, principalmente, a partir das novas propostas para a educação defendidas no Brasil a partir de 2019 pelo atual governo.

\section{Referências}

ALCANTARA, M. Mecanismos de controle nas escolas estaduais paulistas: políticas de bonificação e indicadores de qualidade. 2010. Dissertação (Mestrado em Educação: História, Política, Sociedade) - Pontifícia Universidade Católica de São Paulo, São Paulo, 2010.

BIANCHETTI, R. G. Modelo neoliberal e Políticas Públicas. 2. ed. São Paulo: Cortez, 1999.

BOURDIEU, P. Leçonsurlaleçon. Paris: Leséditions de Minuit, 1992.

BOURDIEU, P. Meditações Pascalianas. Rio de Janeiro: Bertrand Brasil, 2001.

BOURDIEU, P. Reprodução cultural e reprodução social. In: A economia das trocas simbólicas. São Paulo: Perspectiva, 2005b. p. 295-336.

BOURDIEU, P; CHAMPAGNE, P. Os excluídos do interior. In: NOGUEIRA, M.A; CATANI, A. (Org.). Pierre Bourdieu: escritos de Educação. Petrópolis: Vozes, 1998. p. 217-227.

BRASIL. Ministério da Educação. Proposta de Diretrizes para a Formação Inicial de Professores da Educação Básica, em curso de nível superior. Brasília, DF: MEC, maio de 2000.

CAMPOS, R. A Reforma da formação inicial dos professores da educação básica nos anos de 1990: desvelando as tessituras da proposta governamental. 2002. 242 f. Tese (Doutorado em Educação) - Universidade Federal de Santa Catarina, Florianópolis/SC, 2002. Disponível em: <www.ppge.ufsc.br/bancodeteses>. Acesso em: 23 abr. 2013.

CHAUÍ, M. Escritos sobre a universidade. São Paulo: Unesp, 2001. MÉSZÁROS, I. A educação para além do capital. São Paulo: Boitempo, 2005. A teoria da alienação em Marx. São Paulo: Boitempo, 2006.

FERNANDES, M. J. S. As reformas educacionais paulistas e o bônus mérito: impactos sobre o trabalho docente e a organização da escola. In: SEMINÁRIO INTERNACIONAL DE LA RED ESTRADO, 8., 2010, Lima, Perú. 
Educación y trabajo docente en el nuevo escenario latino-americano: Entre la mercantilización y la democratización del conocimiento. Lima, Perú: Universidad de Ciencias y Humanidades, 2010. p. 1-14. CD-ROM.

FRIGOTTO, G. Os delírios da razão. In: GENTILI, P. (Org.). Pedagogia da exclusão. Petrópolis: Vozes, 1995, p. 77-108.

FRIGOTTO, G; CIAVATTA, M. Educação básica no Brasil na década de 1990: subordinação ativa e consentida à lógica do mercado. Educ.

Soc., Campinas, v. 24, n. 82, 2003. Disponível em:

$<\mathrm{http}: / /$ www.scielo.br/scielo.php? =S0101-

73302003000100005\&lng=pt\&nrm=iso>. Acesso em: 23 jan. 2013.

GENTILLI, P. Neoliberalismo e educação: manual do usuário. In: GENTILI, P.; SILVA, T.T. Escola S.A. Brasília: CNTE, 1996, p. 9-49.

HADDAD defende a valorização por mérito dos professores. Veja, Notícias:

Educação, 17 fev. 2010. Disponível em:

$<$ http://veja.abril.com.br/noticia/educacao/haddad-defende-valorizacaomerito-professores>. Acesso em: 12 set 2010.

KOGA, Y. M. N. Magistério e distinção: um estudo sobre as trajetórias das professoras ganhadoras do prêmio Professores do Brasil no meio oeste de Santa Catarina. 2009. Dissertação (Mestrado em Educação: História, Política, Sociedade)- Pontifícia Universidade Católica de São Paulo, São Paulo/SP, 2009.

MELLO, E. M. B. Valorização de profissionalização de professores, carreira profissional docente, qualificação docente e formação de professores: temáticas de teses produzidas no período de 1996 a 2006. In: SEMINÁRIO INTERNACIONAL DE LA RED ESTRADO, 8., 2010, Lima, Perú. Educación y trabajo docente en el nuevo escenario latino-americano: Entre la mercantilización y la democratización del conocimiento. Lima, Perú: Universidad de Ciencias y Humanidades, 2010. p. 1-14. CD-ROM.

MELLO, G. N. Formação inicial de professores para a educação básica: uma revisão radical. São Paulo: MEC, out./nov. 1999. Documento principal: versão preliminar para discussão interna. Datilografado.

PEREIRA, G. R. de M. Servidão ambígua: valores e condições do magistério. São Paulo: Escrituras, 2001. (Coleção Ensaios Transversais)

PEREIRA, G. R. de M; ANDRADE, M. Lucro de ação: um exame das condições de possibilidade do magistério oficial. Revista Brasileira de Estudos Pedagógicos, Brasília, v. 87, n. 215, p. 9-18, 2006. 
PERONI, V. Política educacional e papel do Estado: no Brasil dos anos 1990. São Paulo: Xamã, 2003. p. 21-134

ROSSI. W. G. Capitalismo e educação: contribuição ao estudo crítico da economia da educação capitalista. 2. ed. São Paulo: Moraes, 1980.

SHIROMA, E; CAMPOS, R; GARCIA, R. Decifrar textos para compreender a política: subsídios teórico-metodológicos para análise de documentos.

Perspectiva, Florianópolis, v. 23, n. 2, p. 427-446, jul./dez. 2005.

SHIROMA, E; MORAES, M; EVANGELISTA, O. Política educacional. 4. ed. Rio de Janeiro: Lamparina, 2007.

SILVA, T. A "nova" direita e as transformações na pedagogia da política e na política da pedagogia. In: GENTILI, P.; SILVA, T. T. da (Org.). Neoliberalismo, qualidade total e educação. 3. ed. Petrópolis: Vozes, 1995. p. 9-30.

SILVA, T; GENTILI, P. Escola S.A: quem ganha e quem perde no mercado educacional do neoliberalismo. Brasília: CNTE, 1996.

SPINELI, G. G. F. O absenteísmo laboral docente e uma escola estadual de São José dos Campos e sua relação com o bônus mérito. 2009. 76 f. Dissertação (Mestrado em Educação: História, Política)-Pontifícia Universidade Católica de São Paulo, 2009.

SMITH, A. A riqueza das Nações: investigação sobre sua natureza e suas causas. São Paulo: Círculo do Livro, 1937.

TORRES, R. Melhorar a qualidade da educação básica? As estratégias no Banco Mundial. In: TOMMASI, Livia de; WARDE, Miriam Jorge; HADDAD, Sérgio. (Orgs.). O Banco Mundial e as políticas educacionais. São Paulo: Cortez, 2000. p. 129-186.

VASCONCELOS, L. A. O bônus professor. 2006. 154 f. Dissertação (Mestrado em Educação)-Universidade Metodista de São Paulo, São Bernardo do Campo, 2006.

VICENTINI, P. P. Imagens e representações de professores na história da profissão docente no Brasil (1933-1963). 2002. 212 f. Tese (Doutorado em Educação). São Paulo: Faculdade de Educação, Universidade de São Paulo. 2002.

WEBER, M. A ética protestante e o espírito do capitalismo. São Paulo: Martin Claret, 2001. 
Recebido em: 15 de outubro de 2019 Aprovado em: 14 de maio de 2020 Publicado em: 04 de setembro de 2020 